\title{
Street demonstrations and the media agenda: an analysis of the dynamics of protest agenda-setting
}

Will Jennings, University of Southampton

Clare Saunders, University of Exeter

Forthcoming in Comparative Political Studies 


\begin{abstract}
This paper argues that the agenda-setting power of protest must be understood in dynamic terms. Specifically, it develops and tests a dynamic theory of media reaction to protest which posits that features of street demonstrations - such as their size, violence, societal conflict and the presence of a "trigger" - lead protest issues to be reported and sustained in the media agenda over time. We conduct a unique empirical analysis of media coverage of protest issues, based upon a dataset of 48 large-scale street demonstrations in nine countries. Time series crosssectional analysis is used to estimate the dynamic effects of demonstration features on media coverage of the protest issue. The findings show that violence can increase media attention in the short-term and larger protest size sustains it over the longer-term. The agenda setting power of protest is structured in time.
\end{abstract}

Keywords: agenda-setting, protest, street demonstrations, mass media. 
It is widely recognised that media coverage significantly raises public awareness of political issues promoted by protest movements. As Lipsky (1986, p. 1151) once said: "if protest tactics are not considered seriously by the media ... protest organizations will not succeed. Like a tree falling unheard in the forest, there is no protest unless protest is perceived and projected". Koopmans (2004: 367) even goes so far as to suggest that:

"...the decisive part of the interaction between social movements and political authorities is no longer the direct, physical confrontation between them in concrete locations, but the indirect, mediated encounters among contenders in the arena of the mass media...."

It has long been argued that securing media coverage on protest issues is crucial for giving movement organizations' social standing and validation (Gamson, 1975). It provides them with "discursive opportunities" (Koopmans \& Olzak, 2004), that is, with an unrivalled opportunity to be heard. Yet despite the efforts of protest organizers, some protests fail to get reported. Why? Perhaps yet more importantly, what are the features of street demonstrations that not only secure coverage of protest issues in the first instance, but are also able to sustain it?

Most of the knowledge that political scientists have gleaned about the relationship between the characteristics of demonstrations and a demonstration's chance of securing media coverage is derived - either directly or indirectly - from protest event analysis (for reviews see Olzack, 1989; Earl et al., 2004). This approach seeks to measure and interpret the frequency and characteristics of protests as reported in newspapers (and sometimes additionally in police records), often in cross-national perspective. It has enabled scholars to make huge advances in the development of theoretical approaches for the study of social movements (see, for example, Tarrow, 1994), but has also led critics to question the possibility of deriving an objective account of protest incidence based solely on media reporting. Subsequent research into bias in media reporting of demonstrations has made it possible to gauge which types of demonstration do and do not secure coverage. It has been confirmed by numerous studies that there is an inherent bias in 
media reporting in favour of stories with news value (e.g. McCarthy et al., 1996; Smith et al., 2001; Earl et al., 2004). Amongst other things, it has been shown that large demonstrations associated with an otherwise mediagenic event (such as a major accident or an important international summit), which involve conflict between police and demonstrations, and which are promoting contested or politically salient issues, are more likely to secure coverage. These findings are not too surprising given newsgathering routines. It is known that the stories most likely to be published fit 24-hour news production cycles, are appropriate to newspapers audiences, reflect mainstream values or show some continuity with existing stories and have human interest and/or have strong visual imagery (Galtung \& Ruge, 1986; Bennett, 1996; Shoemaker \& Reese, 1996). More generally, the media tend to favour "episodic" reporting of events (Iyengar, 1991), and have a tendency to select negative information for consideration (Soroka, 2012; 2014).

Yet there are limitations to the extant knowledge base. Whilst we have clues as to which types of demonstration are most likely to gain media attention, few studies consider whether demonstrations can sustain coverage of protest issues over time. This is despite research indicating that dynamics of the reporting of protest events and issues over time are interesting and important. Seguin (2016), for example, found that past media attention increases social movement organisations' chances of securing coverage in the future, and that social movement organisations can gain more coverage after a protest event as their representatives become viewed by journalists as spokespersons for movements. This notion resonates with Gaby and Caren's (2016) concept of 'discursive eruption', illustrated through a case study of Occupy Wall Street. Discursive eruption occurs in the aftermath of a protest once radical movement actors have created discursive opportunities that other organisations capitalise on them into the future. These two studies have addressed the dynamism involved in the reporting of protest issues as a consequence of protest, but both have focused only on a single protest site or single issue rather than multiple protests and multiple issues. Although it is known that the media reacts in different 
ways in the run up to a protest event, at the time of the protest event and after a protest, to particular features of protests, little is known about how this varies across a variety of protest issues. Thus, in this paper we consider the question: what are the features of demonstrations on multiple issues that lead to protest issues being reported and sustained in the media over time?

\section{A Dynamic Theory of Protest and the Media Agenda}

The majority of applications of protest event analysis - even some of the most sophisticated ones - treat media attention as a static observation; as a count of news coverage demonstrations receive over a defined period of time (for a discussion, see Andrews \& Caren, 2010). Only a handful of studies incorporate a distinct temporal element to understand the relationship between protest and media coverage, and most of those that do are focused on media as a mediating variable rather than the outcome of protest. For example, Andrews and Biggs (2006) use event history analysis to trace the diffusion - through mass media, organizations and social networks of sit-ins in the civil rights movement in the 1960s. Similarly, work by Walgrave and Vliegenthart (2012) and Vliegenthart et al. (2016) examines the relationship between protest and institutional agendas over time. All of these accounts seek to measure the effect of protest frequency on the broader issue agenda, again with media coverage being the mediating factor. The general implication of these studies is that higher levels of news coverage of protest activity lead to broader uptake of the related protest issue on the social and political agenda. While we know that there is a link between the incidence of protest and media attention (e.g. McCarthy et al., 1996; Smith et al., 2001; Earl et al., 2004; Maney \& Oliver, 2001) and we know something about the temporal dynamics of protest reporting for single issues (Gaby \& Caren, 2016; Seguin, 2016), little is known about how media coverage of protests, and protest issues, is structured in time across multiple issues.

Protest politics fundamentally concerns the struggle to draw attention to contentious issues and to mobilize support from other actors within the political system - akin to what Schattschneider 
(1960) famously called the "expansion of conflict". Demonstrations are a political resource/strategy intended to be disruptive by shifting the focus and tone of the news agenda. The extent of this disruption might be limited to a change in the next day's front page headlines and running order of television bulletins that is quickly forgotten, or extend over the weeks that follow to an escalation of media interest that attracts further coverage over time. Whether or not the discursive opportunities that are opened up by demonstrations persist over more than a short period is likely to determine whether they have lasting effects on the outcomes of political conflict. This matters because we know more broadly that media attention is skewed and subject to explosive shifts in focus, such that only a selection of issues get reported (Boydstun, 2013). As discussed above, media coverage of social movement organisations has specifically been shown to exhibit positive feedback processes, producing "cascades of attention" (Seguin, 2016). Street demonstrations can thus be conceptualized as shocks to the media agenda that unfold in different ways over time, either persisting or decaying.

We are thus interested in whether the effects of demonstrations take the form of temporary "bounces" or more enduring "bumps" in media coverage of protest issues. Or do some elements of the shock to the media agenda decay more rapidly than others? These are questions about how media attention is sustained not only at the time of the demonstration, but in the weeks following it. This matters because the effectiveness of a demonstration is likely to stem not just from attracting headlines regarding the event in the next day's papers, but also from leading to a sustained shift in media focus, onto the issues that the demonstration raises. It also matters because the mass media is an important channel for bringing about changes in public opinion and public policy (e.g. Iyengar \& Kinder, 1987; Iyengar, 1991; Baumgartner \& Jones, 1993; Soroka, 2002; Walgrave et al., 2008).

Although we know which features of demonstrations are associated with news coverage, little is known about the features of demonstrations that sustain coverage. And while we know that 
'discursive eruption' has occurred in newspapers' discourses of inequality after Occupy Wall Street, we do not know whether this particular dynamic is generalisable to other protest issues. We draw on lessons from studies on protest coverage and political communication to develop hypotheses concerning how demonstration characteristics lead to different forms of media reaction over time. ${ }^{1}$

\section{Dynamic Effects of Protest on the Media Agenda}

The ways in which processes of conflict and attention-shifting can elevate an issue onto the political agenda is at the heart of agenda setting theories (e.g. Schattschneider, 1960; Downs, 1972; Kingdon, 1984; Baumgartner \& Jones, 1993; Jones \& Baumgartner, 2005). Moreover, the way in which the media package news for consumption tends to favour episodic bouts of attention above sustained coverage of social issues and problems (see Iyengar, 1991).

Consider possible dynamic forms of media effect induced by protest activity. A public demonstration might produce a spike in news coverage during the week of the event, leading to increased attention to the issue, and then dissipate immediately, leaving no lasting imprint on the media agenda. Such a dynamic response would have no long-term consequence for political conflict on the issue. Alternatively, a large scale demonstration might lead to a permanent shift in the amount of news coverage dedicated to the issue in the weeks following it, contributing to a lasting increase in consciousness among political actors and citizens. Or the impact on media coverage might be graduated, slowly gaining in prominence over time or decaying after an initial spike in attention. Of course, the form of dynamic response might be a hybrid, combining elements of these processes. Indeed, Downs' (1972) issue attention cycle and Baumgartner and Jones' (1993) punctuated equilibrium theory are each premised on the idea that such shocks to issue attention may dissipate over time but still lead to permanent shifts in the long-term

\footnotetext{
${ }^{1}$ We do not differentiate here between expected differences in news media reporting of events, such as between television and newspapers (Lipsky 1968: 1152), though this clearly is a line for future research.
} 
equilibrium. Boydstun's (2013) model of news generation similarly identifies explosive shifts in attention that intersperse long periods of stability in the media agenda.

Figure 1 displays a series of hypothetical forms of dynamic response of media coverage to demonstrations (drawing on Box and Tiao, 1975). In time series models, these dynamic responses are termed "transfer functions" (discussed further below). The top-left panel depicts a situation where a spike in news coverage during the week of the demonstration is temporary, dissipating completely by the following week (a pulse intervention). The top-right panel, in contrast, shows a situation where that spike in news coverage persists in its entirety after the event (a step intervention). This implies that the demonstration leads to a permanent change in media attention to the issue. The bottom-left panel depicts a situation where the response of media to the demonstration is gradual, with attention to the related issue increasing or decreasing at a linear rate in the weeks following the event, for example as societal awareness grows or as new issues enter the agenda (a ramp intervention). Often, the dynamic response will combine elements of these forms: where some portion of the shock to media coverage of the issue persists, while other parts of it decay, leaving attention at a new equilibrium. This sort of hybrid is shown in the bottom-right panel. 
Figure 1. Types of Media Effect
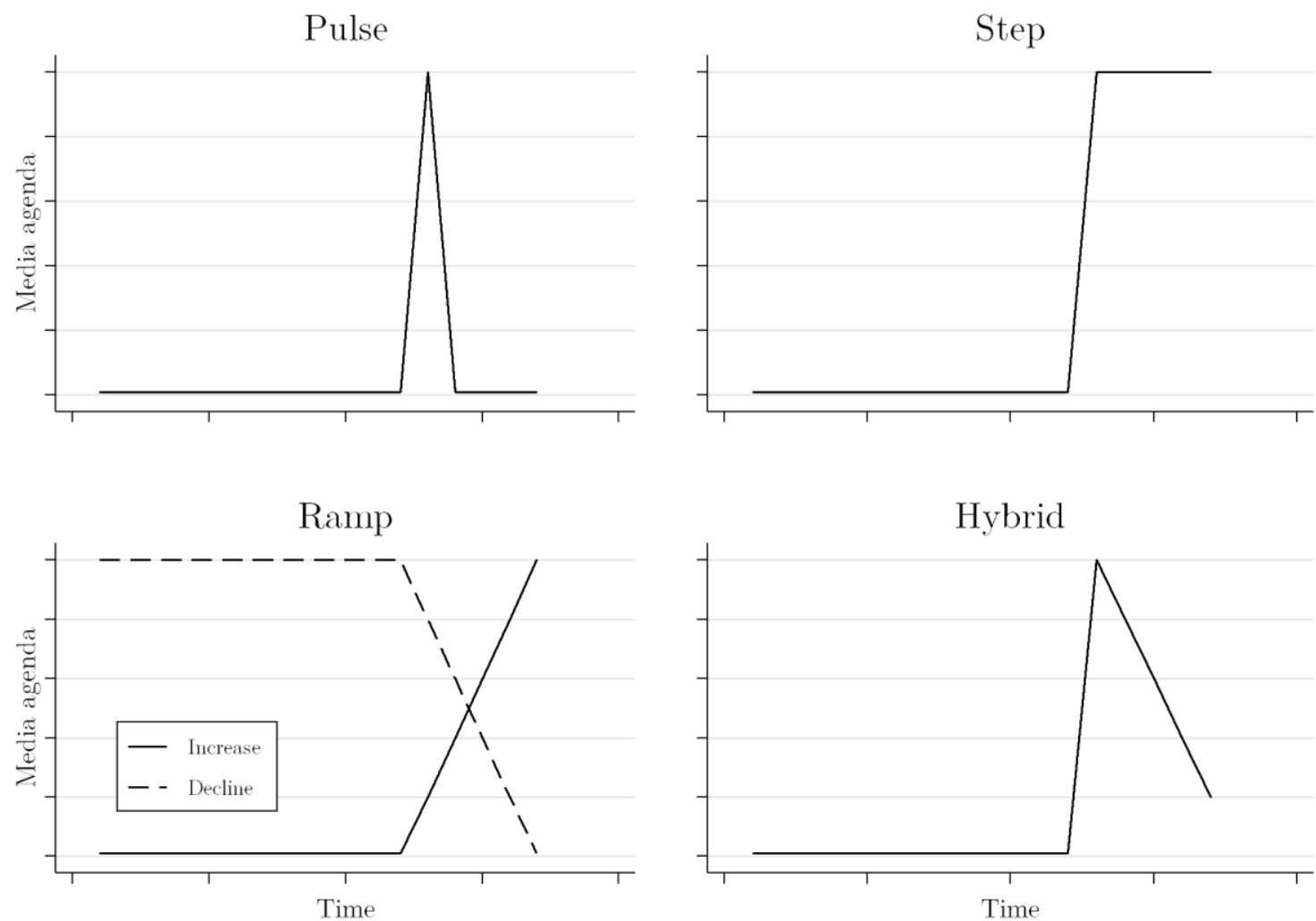

\section{Theoretical expectations}

As we noted, the conventional approach to analysis of protest agendas has been mostly concerned with static relationships. We here reflect on how factors relating to protest size, conflict, violence and the presence of trigger events may have dynamic effects on media coverage of multiple protest issues. It is well-established that larger demonstrations tend to attract more news coverage than smaller ones (e.g. McCarthy et al., 1996; Barranco \& Wisler, 1999). How might this play out over time? Large protests attract media attention due both to the value of spectacle for news reporting and the participation of particular groups or wider society which engages interest. When there is competition among news stories (Soroka, 2012; Boydstun, 2013; Bennett, 2016), a large demonstration is more likely to generate news by attracting the interest of "gatekeeper" journalists and news outlets. We therefore anticipate that larger demonstrations will secure higher levels of attention for protest issues, relative to smaller demonstrations, during the immediate aftermath of the event. This is because news coverage will be temporarily attracted to 
the issue as a human interest story, consistent with Iyengar's (1991) arguments regarding media bias towards news stories with "episodic" frames (i.e. news frames that are event-oriented) (as noted in Smith et al., 2001 and Shoemaker \& Reese, 1996). However, we also would expect that large demonstrations - through signalling commitment and salience - produce an effect on media coverage that lasts beyond the short-term by raising awareness and popularising issues in wider debate. These "thematic" frames can alter understanding of social and political problems. Lastly, we would expect that in a crowded issue agenda (Jones \& Baumgartner, 2005; Soroka, 2012; Boydstun, 2013), where the media is constantly searching for new stories and issues, this increase in coverage of the protest issues will dissipate, as media interest wanes and other events and issues become salient. These theoretical expectations inform our first hypothesis:

$H_{1}$ : a higher number of demonstration participants will increase media coverage of protest issues in the immediate aftermath of the event leading to an increase over time that eventually decays.

Past studies find that protest events involving conflict between different groups or actors are most likely to gain coverage (e.g. McCarthy et al., 1996; Smith et al., 2001). Such stories play into the hands of the journalistic norm of balance. As reporters strive to be objective, stories that present both sides "for" and "against" an issue are often prioritised (Boykoff, 2007). This interest in conflict is consistent with more general negativity bias in news selection by mass media (Soroka, 2012). A counter-demonstration might additionally lead to more media coverage of protest issues in the short-term, since this is typically indicative of broader social and/or political conflicts around issues of concern - and will often produce a captivating storyline for news coverage. Specifically, attention to issues is expected to increase in the immediate aftermath of such counter-protests due to the resulting "expansion of conflict" (Schattschneider, 1960), but this may also be sustained in the weeks that follow the demonstration. Once an issue has become conflictual, it is more likely to be subjected to pack journalism, as reporters descend en masse on associated characters and events (Matusitz \& Breen, 2012). Since presence of a counter demonstration indicates highly contentious issues which are likely to attract attention more 
widely - due to the societal interest and their mediagenic nature - there should also be a lasting increase in media coverage. This informs our second hypothesis:

$H_{2}$ : broader social and/or political conflict will increase attention to protest issues in the short-term and that increase will be sustained in the weeks following a demonstration

Violent demonstrations tend to receive more coverage in the media (e.g. Barranco \& Wisler, 1999; Smith et al., 2001), attributable again to the episodic nature of media agendas (Iyengar, 1991; Shoemaker \& Reese, 1996) as well as pointing to wider social and political conflicts around an issue. But how might violence impact the extent to which the media picks up protest issues beyond coverage of the event itself (which is likely to have a relatively short-lived issue-attention cycle)? The powerful imagery of a riot can temporarily "authenticate the politically volatile content" (Bennett, 1996, p. 337). In this sense it becomes a news icon, but one that only temporarily allows marginalized ideas to come to the centre of the news. Violence could have a counter-productive impact on newspaper coverage in the medium-term, since it lacks consonance with existing socio-cultural scripts (Galtung \& Ruge, 1965) and makes the protest issue appear to threaten/disrupt the status quo (Smith et al., 2001). This dampening of media attention need not be permanent, but might be expected to temporarily depress the willingness of newspapers editors to give newspaper inches to an issue associated with illegitimate or riotous means. As Lipsky (1968, pp. 1152-3) argues, confrontational tactics might alienate allies or lead to the exclusion of protest groups from mainstream debate and bargaining - at least for the period of time in which the demonstrations are recent in observers' memories. This leads to our third hypothesis:

$H_{3}$ : higher levels of violence at demonstrations will increase the level of media coverage of protest issues in the short-term, but will depress it in the weeks following the demonstration.

Lastly, association of a demonstration with a topical or high profile event might provide media with a convenient peg around which to organise their reporting of the protest issue (McCarthy et 
al., 1996; Shoemaker \& Reese, 1996). Events are also likely to be associated with press releases from official sources, known to be a major source of news (Gandy, 1982). In the spirit of pack journalism, a major or unusual public event, such as a G8 summit or official state visit, ensures that media will already be covering the event and will be searching for related news stories. Consequently, a close link between a demonstration and some sort of prominent trigger event might temporarily elevate the level of media coverage of the wider protest issue - but this declines during the weeks that follow due to the episodic nature of the media agenda (Boydstun, 2013). The next event befitting to a 24-hour news cycle will take its place unless there is a broader socio-political conflict (see $\left.\mathrm{H}_{2}\right)$. This informs our fourth hypothesis.

$H_{4}$ : the presence of a trigger event will increase media coverage of the protest issue in the short-term, but this effect will decay with time.

Our expectations are summarised in Table 1.

Table 1. Static and Dynamic Expectations of Media Coverage of Protest Issues

\begin{tabular}{|l|l|l|}
\hline & Static & Dynamic \\
\hline Number of participants & $\begin{array}{l}\text { More coverage for } \\
\text { large demonstrations }\end{array}$ & $\begin{array}{l}\text { More attention in the short-term (protest attracts news } \\
\text { coverage), but also will lead to more attention in longer- } \\
\text { term agenda by signalling commitment and salience of } \\
\text { protest issue }\end{array}$ \\
\hline $\begin{array}{l}\text { Social and/or political } \\
\text { contentiousness } \\
\text { (presence of a counter } \\
\text { demonstration indicates } \\
\text { multiple interests) }\end{array}$ & $\begin{array}{l}\text { More coverage for } \\
\text { demonstrations on } \\
\text { highly contentious } \\
\text { issues }\end{array}$ & $\begin{array}{l}\text { More attention in the short-term as event adds to the } \\
\text { storyline for news reports, but also increases media } \\
\text { coverage of issue generally, i.e. social/political conflict } \\
\text { attracts attention (in the Schattschneiderian sense) }\end{array}$ \\
\hline Exhibit violence & $\begin{array}{l}\text { More coverage for } \\
\text { demonstrations where } \\
\text { violence breaks out }\end{array}$ & $\begin{array}{l}\text { More attention in the short-term, but depresses coverage } \\
\text { of the issue in the longer-term, i.e. potentially self- } \\
\text { defeating (short-term gain but long-term costs) }\end{array}$ \\
\hline Trigger event & $\begin{array}{l}\text { More coverage where } \\
\text { there is a 'trigger' } \\
\text { event relating to the } \\
\text { demonstration, such } \\
\text { as a G8 meeting }\end{array}$ & $\begin{array}{l}\text { More attention in short-term, i.e. coverage during the } \\
\text { week of the protest/trigger event }\end{array}$ \\
\hline
\end{tabular}

\section{Data and Methods}

This analysis is based upon a dataset of 48 street demonstrations in nine countries, collected through the research project Caught in the Act of Protest: Contextualising Contestation 
(www.protestsurvey.eu). The project is the first systematic cross-national survey of large-scale street demonstrations and collection of contextual data (on media attention and protest organizations), with data collected for demonstrations in Belgium, the Czech Republic, Denmark, Germany, Netherlands, Spain, Sweden, Switzerland and the UK. These events all occurred during the period between 2009 and 2013, and provide for substantial variation across our dependent variable (see below). ${ }^{2}$ The demonstrations vary in size from around 500 to several hundred thousand participants, but each was a physical manifestation of protest that lasted at least several hours but no more than 24 hours. $^{3}$

Our investigation takes the form of time series cross-sectional data, where the dependent variable is the level of national media attention to the related issue over a sequence of time points and where each demonstration is a separate panel. This enables us to derive insights into the general structure of protest media agendas and variation across context. The dependent

\footnotetext{
2 The Caught in the Act of Protest dataset includes over 80 demonstrations, but our final analysis is based upon a subset of 48 demonstrations. A number of cases are dropped due either to missing data on media attention or organisational characteristics. Demonstrations that lasted more than 24 hours (e.g. Occupy protests) were also dropped. We do not claim that our sample is representative of all demonstrations in Europe 2009-2013 (Anduiza \& Cristancho, 2011). However, the fact that the sample is constructed independently of a protest analysis is a huge advantage of our research. Studies on media coverage of protest are usually based on events reported in the media. In this study, a sample of large-scale demonstrations was derived independently from their status in the newspapers. Despite missing data, we are therefore confident that a broad cross-section of protests is covered.

${ }^{3}$ It is an advantage of our empirical design that our sample of protests is broadly comparable in terms of size and duration. Protest event analysis has viewed "gatherings of two of more people in which a visible or audible "claim" is made which, if realized, would affect the interests of some specific person(s) or group(s) outside their own numbers" (Tilly, 1978, p. 275) as a unit of analysis. Thus, a 3-day vigil outside the White House is counted as one protest, but a daily two-hour picket repeated every day of the week is counted as several protests. We include only demonstrations that had over 500 participants, and which lasted from several hours to one day. Occupy London, for example, was excluded due to it having taken place over a period of longer than 24-hours unlike all other demonstrations in our dataset.
} 
variable consists of a total count of newspaper articles mentioning the protest issue across a total of four newspapers per country: that is two main broadsheets and two main popular (i.e. tabloid) newspapers. The protest issue is broadly defined to capture the societal issues related to each demonstration as framed in the call to action. Up to five search terms were used for each protest issue across four newspapers: the two main quality newspapers and the two main popular newspapers (see the Supplementary Materials, Table S5 for further details of the newspapers analysed). For the National Climate Change March (2009), for example, the keywords reflecting the general issue were taken from the call to action. We searched for 'climate change', 'global warming', 'climate emergency', 'dirty coal' and 'green jobs'. Note that this differs from the more episodic coverage of demonstrations themselves, which in data collection were searched for using the general search term in addition to the word 'demonstration' or 'march' (Klandermans et al., 2010). Keyword counts were conducted on a weekly basis for twelve weeks before the demonstration, the week of the demonstration and four weeks after.

Our independent variables are the number of participants on a demonstration (we took an average of researchers', police and organisers' estimates of the number of people that attended the event, in order to reduce potential biases in assessments, see Biggs, 2018); the observed presence of a counter-demonstration (using data collected by field researchers); the extent of violence (measured by field researchers) and the presence or absence of a trigger event (coded by senior researchers in each country team). See Appendix 1 for further detail of the coding and measurement of our variables.

In addition, we include the following control variables: country, issue category and media tone. Country dummies (i.e. country fixed effects) are included because variation in media systems and cultures across nations could lead to differential levels of media coverage across cases. Regarding issues, past evidence from protest event analysis suggests that some protest issues tend to receive more media attention than others. The women's movement is generally under-represented in the 
mass media, for example, whereas immigration and unemployment are generally more salient (McCarthy et al., 1996; Koopmans, 2004, p. 371; van Zoonen, 1992). Additionally, media tone is included to account for a potential weakness in protest event analysis, which fails to recognise whether the media is elevating a protest issue with positive coverage, or deflating it by reporting negatively. An outright negative tone is very easy to spot, since it involves portraying activists as "folk devils". This involves representing them as mindless and/or violent thugs that are destructive and dangerous (Donson et al., 2004, see also Bennett, 2003 on media reporting of anti-capitalist protest; see page 20 for the operationalisation of 'tone').

Pooled time series cross-sectional analysis of this sort offers a simultaneous solution to understanding temporal dynamics and the role of context in whether or not demonstrations are able to influence the societal agenda. Further, the interaction of these contextual variables with transfer functions (i.e. pulse, step and ramp interventions) enables us to establish whether the timing of any effect was transient and limited to the week of the demonstration, led to a step change in the level of media coverage, or resulted in a temporary spike in media attention but decayed over time. This offers a novel dynamic approach to understanding the agenda-setting power of demonstrations. The design of our study is large- $\mathrm{N}$ (based on a sample of demonstrations, avoiding the tautology endemic to many studies of media attention to protest, which select cases based on their being reported in the media), at the same time as putting protest in context.

The Media Agenda

Consider the dependent variable of our study. We use the number of newspaper stories about the main issue(s) related to the demonstration over a 17 week period - which covers the full period of time for which the Caught in the Act of Protest project collected data. This includes approximately the three months (i.e. 12 weeks) before the demonstration, the week of the event 
itself, and the month (i.e. four weeks) following it. ${ }^{4}$ This provides a measure of the prominence of the related issue on the societal agenda. This time period has the advantage of observing the media salience of the protest issue well in advance of the demonstration, and after immediate coverage of the event itself has faded. We can therefore ascertain whether the effect of the demonstration on the media agenda persists, relative to its previous level, and beyond eventoriented episodic news frames (Iyengar, 1991). By the end of the four-week period following the protest, whether or not a protest issue is still the subject of news coverage - in competition with numerous other issues and stories - offers a good indication of the degree to which demonstrations leave more than an episodic imprint on the media agenda.

Note that the time serial property of our data has important implications for the analysis and the sorts of inference that can be drawn. Firstly, data measured at successive points in time often are related, meaning that time series analysis must control for autocorrelation of the observations. Simply, the media agenda in week $t$ is a function of the agenda in week $t-1$. Secondly, once the time dependence of our data has been dealt with, it is possible to determine whether the timing of a demonstration and its features, are associated with a transient or lasting shift in media attention to an issue. Thirdly, because we have a large number of identically constructed media agenda timelines, it is possible to consider both the general structure of media agendas for largescale demonstrations and variation due to context - such as features of the demonstration and its policing, its organization, or differences across issues or countries. The media timeline for each of the 48 demonstrations are plotted in Figure 2 (see Appendix 2 for the list of demonstrations

\footnotetext{
${ }^{4}$ Because of the composition of our dataset, our analysis of post-event media effects is limited to the four-week window following the demonstration. While this prevents us from drawing inferences about the long-term impact on the societal agenda, it remains possible to determine whether or not the media footprint of the event lasted substantially beyond the day of the event. Because most news reporting of demonstrations tends to be concentrated on the day of the event, or the day after, we believe this four-week period has face validity as a measure of the postevent media agenda.
} 
and their ID number). ${ }^{5}$ Visual inspection of the data suggests that these media agendas exhibit similar features - with many exhibiting a distinct spike or step in the week of the protest, often decaying thereafter - but with variation across cases too. We discuss two contrasting cases (demonstrations 15 and 28) towards the end of our results section.

Figure 2. Media Agendas in 48 Large-Scale Demonstrations

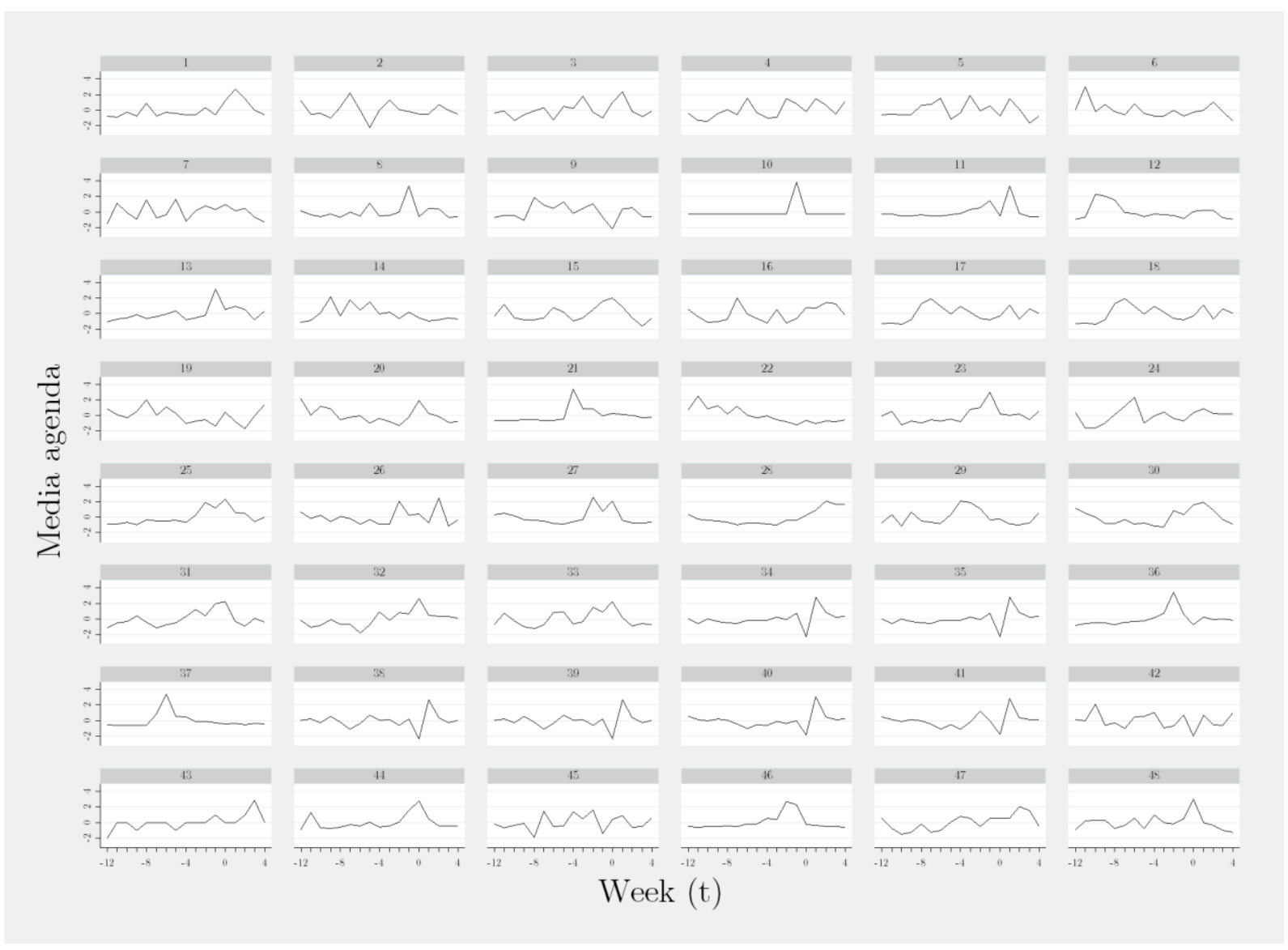

\footnotetext{
${ }^{5}$ For purposes of comparison across demonstrations, the number of newspaper articles is standardised within cases (allowing us to use a common y-axis for the figure). Our time series cross-sectional analysis uses the untransformed number of news articles as the dependent variable.
} 


\section{Time Series Cross-Sectional Analysis}

In the analysis that follows, we undertake time-series cross-sectional analysis of media attention to issues associated with large-scale demonstrations. We first model the dynamic character of protest media agendas on a week-by-week basis using pulse, step and ramp transfer functions. This allows us to better understand the temporal structure of media attention to issues that are elevated to the societal agenda by large-scale demonstrations. We then proceed to develop a dynamic model of the media agenda that considers effects of the transfer functions for demonstration size $\left(\mathrm{H}_{1}\right)$, presence of a counter-demonstration $\left(\mathrm{H}_{2}\right)$, aggressiveness of protestors and the police $\left(\mathrm{H}_{3}\right)$ and the presence of a trigger event $\left(\mathrm{H}_{4}\right)$.

\section{The Dynamics of Media Coverage of Protest Issues}

To first examine the dynamic properties of the media agenda on a week-by-week basis, a time series cross-sectional first order autoregressive, $\operatorname{AR}(1)$, model is estimated for media attention to protest issues associated with 48 demonstrations (i.e. panels). This model specification has the advantage of controlling for temporal persistence of media coverage, while estimating its common structure across all demonstrations. ${ }^{6}$ The full model takes the form:

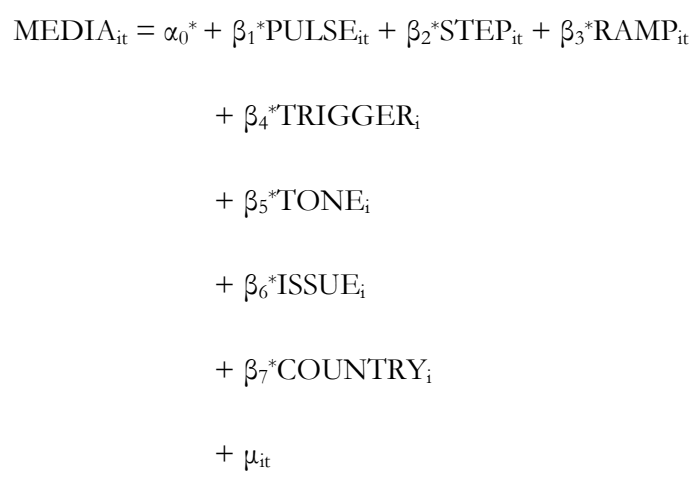

\footnotetext{
6 Prior to modelling, the dependent variable (i.e. the media agenda for each demonstration) was tested for the presence of unit root in the panel data using a Fisher-type (Choi, 2001) test. Based on the combined $p$-values of Augmented Dickey-Fuller tests of individual panels (at three lags) this rejects the null hypothesis that all panels contain a unit root at the 95 per cent confidence level. Data are therefore modelled in level form rather than in first differences.
} 
Where MEDIA $_{\text {it }}$ refers to the number of newspaper stories related to the general issue of a given demonstration $i$ at time $t, \alpha_{0}{ }_{0}$ represents the intercept, with a series of dynamic responses: where PULSE $_{\text {it }}$ refers to the temporary change in the media agenda during the week of the

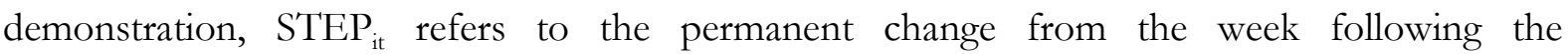
demonstration onwards, and $\mathrm{RAMP}_{\text {it }}$ refers to a gradual trend capturing a linear increase or decrease in attention from the week following the demonstration. ${ }^{7}$ This instantaneous timing of the pulse intervention and lagged timing of the step and ramp interventions enables us to determine whether there is an initial change in the media agenda before transition to a new longer-run state. The model includes a control for whether the general tone of media coverage is positive or negative $\left(\mathrm{TONE}_{\mathrm{j}}\right.$ ), coded by the research team on a scale from 1 where media coverage is largely positive and 7 where it is largely negative.

The model is estimated with panel-corrected standard errors (Beck and Katz, 1995), which controls for panel heteroscedasticity and contemporaneous correlations of the errors. The latter is especially important to control for given the data we are using because some of the demonstrations relate to the same issue (i.e. where demonstrations were held in parallel in multiple countries), while demonstrations on unrelated issues occurred during an overlapping time period. The model is fitted with the Prais-Winsten method to test for serial autocorrelation $\left(\mu_{\mathrm{it}}\right)$, with the rho estimated separately for each panel as the first-order autoregressive process: $\mu_{\mathrm{it}}$ $=\varrho \mu_{\mathrm{it}-1}+\varepsilon_{\mathrm{it}}$. This allows the rate of persistence to vary across units (i.e. panels) consistent with the expectation that persistence of the media agenda will vary on a demonstration-bydemonstration basis, reflecting features distinct to particular local contexts. Country$\left(\right.$ COUNTRY $\left._{j}\right)$ fixed effects are included to allow the mean level of media attention to vary

\footnotetext{
7 Where the week of the demonstration is $t=0$, PULSE $\mathrm{ij}_{\mathrm{ij}}$ is defined such that: $x_{t}=\left\{\begin{array}{l}0, t \neq 0 \\ 1, t=0\end{array}\right.$, STEP $\mathrm{ij}$ is defined such that $x_{t}=\left\{\begin{array}{l}0, t<1 \\ 1, t \geq 1\end{array}\right.$, and RAMP ij is defined such that $x_{t}=\left\{\begin{array}{l}0, t<1 \\ t, t \geq 1\end{array}\right.$.
} 
national media, while issue-level (ISSUE $)_{i}$ fixed effects are included for the full model. ${ }^{8}$ In the absence of directly comparable cross-national survey measures of public opinion, the latter provide a measure of the salience of each type of protest issue. ${ }^{9}$ The results of the baseline models, including the individual functional forms without controls (i.e. issue fixed-effects and tone), and the full model (with and without controls) are presented in Table 2.

Table 2. The Dynamics of Media Coverage of Protest Issues

\begin{tabular}{|c|c|c|c|c|c|}
\hline \multirow[b]{2}{*}{$\overline{\text { PULSE }_{i j}}$} & \multicolumn{5}{|c|}{ MEDIA $_{\text {it }}$} \\
\hline & $\begin{array}{c}-5.64 \\
(10.92)\end{array}$ & & & $\begin{array}{r}13.77 \\
(13.00)\end{array}$ & $\begin{array}{c}13.71 \\
(12.97)\end{array}$ \\
\hline $\mathrm{STEP}_{\mathrm{ij}}$ & & $\begin{array}{c}20.08 \\
(15.61)\end{array}$ & & $\begin{array}{c}71.55 \\
(20.85)^{* *}\end{array}$ & $\begin{array}{c}72.55 \\
(20.73)^{* *}\end{array}$ \\
\hline $\mathrm{RAMP}_{\mathrm{ij}}$ & & & $\begin{array}{l}-2.54 \\
(6.94)\end{array}$ & $\begin{array}{l}-22.33 \\
(6.55) * *\end{array}$ & $\begin{array}{l}-22.46 \\
(6.52)^{* *}\end{array}$ \\
\hline TONE $_{\mathrm{i}}$ & & & & & $\begin{array}{r}8.44 \\
(8.81)\end{array}$ \\
\hline ISSUE1 $1_{\mathrm{i}}$ : Economic & & & & & $\begin{array}{r}7.28 \\
(49.32)\end{array}$ \\
\hline ISSUE2: Environment & & & & & $\begin{array}{r}28.25 \\
(49.83)\end{array}$ \\
\hline ISSUE3i: Rights & & & & & $\begin{array}{r}53.45 \\
(47.41)\end{array}$ \\
\hline ISSUE4 $4_{\mathrm{i}}$ : Other & & & & & $\begin{array}{r}40.23 \\
(46.52)\end{array}$ \\
\hline Intercept & $\begin{array}{c}86.71 \\
(21.59)^{* *}\end{array}$ & $\begin{array}{c}82.00 \\
(23.45)^{* *}\end{array}$ & $\begin{array}{c}86.11 \\
(21.71)^{* *}\end{array}$ & $\begin{array}{c}82.59 \\
(20.94)^{* *}\end{array}$ & $\begin{array}{c}28.61 \\
(61.82)\end{array}$ \\
\hline$R^{2}$ & 0.41 & 0.42 & 0.42 & 0.43 & 0.43 \\
\hline Panels & 48 & 48 & 48 & 48 & 48 \\
\hline$N$ & 816 & 816 & 816 & 816 & 816 \\
\hline
\end{tabular}

$* p<0.05$; $* *<<0.01$; Note: the reference category for issue type is those demonstrations that relate to peace.

\footnotetext{
${ }^{8}$ Demonstration issues are aggregated into five categories from the Caught in the Act dataset: economic (antiausterity, labour issues), environment (climate change, nuclear), rights (democracy, LBGT, minorities, women), peace (peace) and other (culture, regional, students, other). Country fixed effects, treating the UK as the reference category, are omitted from the results but are available in the supplementary materials.

9 As a robustness check, we also tested for the effect of political system characteristics on the level of media attention. This suggests that federal systems (Belgium, Germany, Switzerland) exhibit less attention to protest issues, but inclusion of this control does not improve the model fit at all (i.e. the R-squared remains unchanged and none of the effects change substantively). If the political system variable is included instead of the country variables, the model fit drops substantially, indicating that there is more variation within systems than across them.
} 
Our findings suggest a distinct pattern of the dynamic response of media coverage of protest issues to occurrence of a large-scale street demonstration. The baseline models including the individual transfer functions do not find significant effects for the pulse, step and ramp interventions. More importantly, however, the step and ramp functions are significant when included in combination. This illustrates the importance of testing for alternative functional forms: if the dynamic response of the media agenda takes the form of a level-increase followed by a decay, the linear form of step or ramp interventions will not adequately fit the underlying data (as the baseline models confirm). ${ }^{10}$ In the full model, the positive and significant effect for the $\mathrm{STEP}_{\mathrm{ij}}$ intervention indicates there is an increase of 72.6 in the average number of newspaper stories about the issue that persists in the period following the week of the demonstration. The negative and significant effect of the $\mathrm{RAMP}_{\mathrm{ij}}$ intervention indicates that news coverage of the protest issue declines by 22.5 newspaper stories a week over the final four weeks of the media timeline. Notably, the PULSE $\mathrm{i}_{\mathrm{ij}}$ intervention is not significant, indicating that while the event is associated with a step-shift and gradual decay in attention, no portion of the shock is entirely temporary (at least for the period in question). Note that the Caught in the Act project also collected a 'protest event analysis' measure that required a specific reference to the 'protest', 'rally' or 'demonstration'. If the dynamic response of this media agenda is modelled, we find a significant pulse intervention - suggesting that this 'episodic' framing precedes broader shifts in attention to protest issues. Our findings on the shape of dynamic responses of the media agenda are of substantive importance, since they are consistent with the expectation that large-scale

\footnotetext{
${ }^{10}$ By their construction, the step and ramp functions are highly collinear as are (consequently) their interactions. This is common when testing competing functional forms, and we do not consider it problematic for specification of the models reported in either Table 2 or 3 (a feature of multicollinearity is that it increases the standard errors of coefficients, so reduces the likelihood of finding significant effects).
} 
public demonstrations can have a lasting effect in elevating issues onto the agenda, even if their half-life in news terms remains quite short before other issues displace them. ${ }^{11}$

Figure 3. Predicted Level of Media Coverage

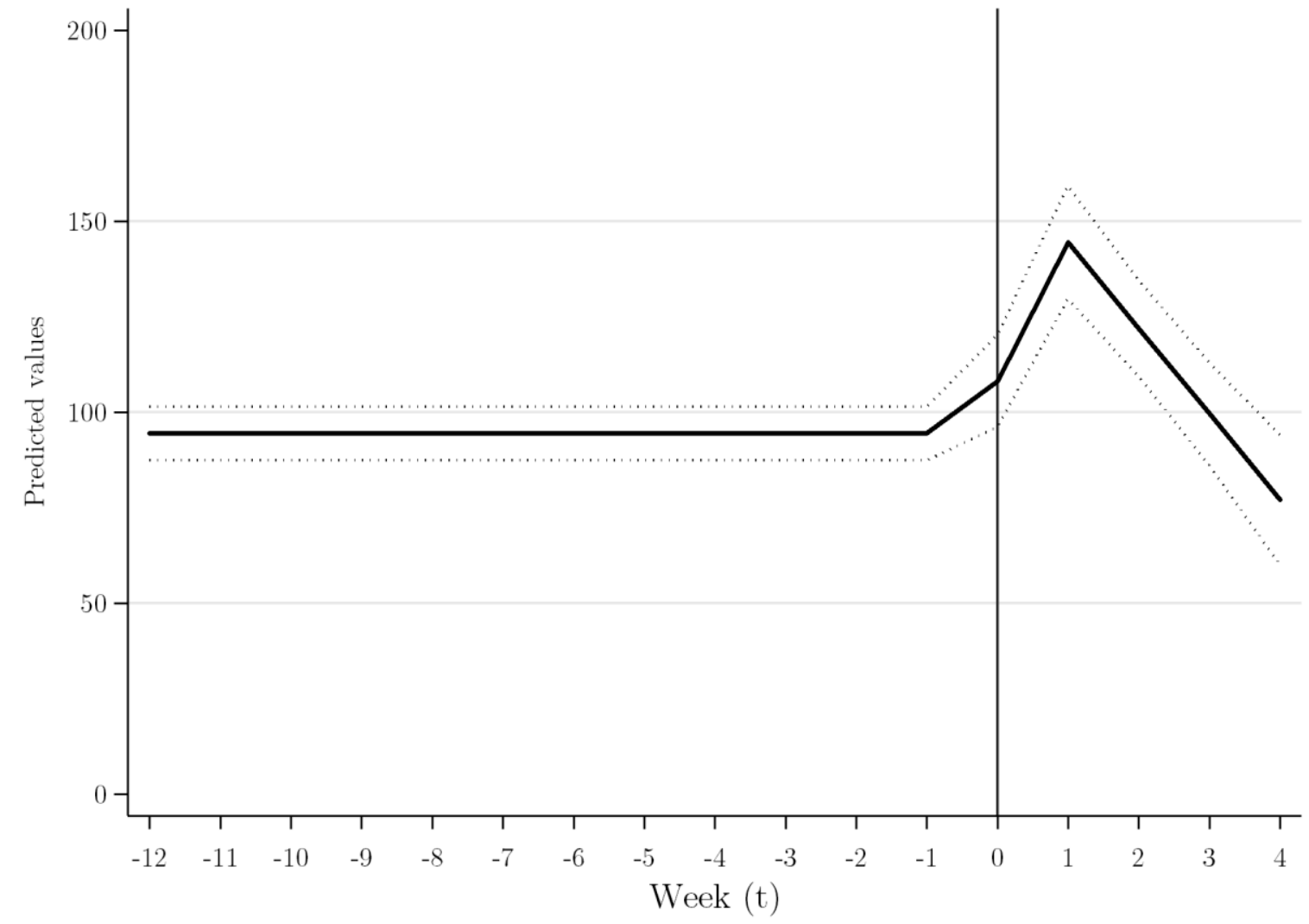

In Figure 3 we present the overall margin, which predicts the level of media coverage (i.e. the total count of newspaper articles mentioning the protest issue) for each week of the timeline, holding all variables in the model constant. The estimates are stable for the first twelve weeks as there is no variation in the dynamic transfer functions. During the week of the demonstration itself $(t=0)$, the initial increase in predicted media coverage is relatively small, peaking instead the following week $(t=1)$. After this time point, the amount of media coverage declines. This pattern

\footnotetext{
11 While the length of the time series for each of the demonstrations (i.e. panels), $\mathrm{T}=17$, limits the possibility for analysis of individual cases, if an $\operatorname{AR}(1)$ model is estimated with pulse, step and ramp interventions, the step and ramp effects are signed in the same direction in 35 out of 48 cases (and are significant at the 95 per cent confidence level in 10 out of those 35 cases). This general pattern therefore appears to hold across the majority of cases.
} 
of dynamic response is consistent with the idea of an issue attention cycle in media coverage of protest issues.

\section{The Dynamics of Contextual Effects on Media Coverage of Protest Issues}

We next consider features of demonstrations that might influence the level of newspaper coverage received by the general issue on which demonstrations focus. As we hypothesized, we expect demonstration size, the presence of a counter-demonstration, the behavior of demonstrators and the police, and the presence of a trigger event will influence the amount of news coverage of protest issues. Alone this offers a static test of whether the protest context (e.g. the scale of the demonstration, level of issue conflict, and the aggression of police and demonstrators) is associated with more or less news coverage both before and after the event. Because these features are located in time it is also essential to consider whether these contextual factors matter more (or less) during the week of the demonstration and/or afterwards. For this reason, we consider interaction of these contextual variables with our transfer functions, as described above. This model can be expressed:

$$
\begin{aligned}
& \operatorname{MEDIA}_{\mathrm{it}}=\alpha_{0}{ }^{*}+\beta_{1}{ }^{*} \operatorname{PULSE}_{\mathrm{ij}}+\beta_{2}{ }^{*} \text { STEP }_{\mathrm{ij}}+\beta_{3}{ }^{*} \mathrm{RAMP}_{\mathrm{ij}} \\
& +\beta_{4}{ }^{*} \operatorname{SIZE}_{\mathrm{i}}+\beta_{5}{ }^{*}\left(\mathrm{SIZE}_{\mathrm{i}} \times \operatorname{PULSE}_{\mathrm{ij}}\right)+\beta_{6}{ }^{*}\left(\mathrm{SIZE}_{\mathrm{i}} \times \mathrm{STEP}_{\mathrm{ij}}\right)+\beta_{7}^{*}\left(\mathrm{SIZE}_{\mathrm{i}} \times \mathrm{RAMP}_{\mathrm{ij}}\right) \\
& +\beta_{8}{ }^{*} \text { COUNTER }_{\mathrm{i}}+\beta_{9}{ }^{*}\left(\text { COUNTER }_{\mathrm{i}} \times \text { PULSE }_{\mathrm{ij}}\right)+\beta_{10}{ }^{*}\left(\text { COUNTER }_{\mathrm{i}} \times \text { STEP }_{\mathrm{ij}}\right)+\beta_{11}{ }^{*}\left(\text { COUNTER }_{\mathrm{i}} \times \text { RAMP }_{\mathrm{ij}}\right) \\
& +\beta_{12}{ }^{*} \text { DEMPOL }_{\mathrm{i}}+\beta_{13}{ }^{*}\left(\text { DEMPOL }_{\mathrm{i}} \times \text { PULSE }_{\mathrm{ij}}\right)+\beta_{14}{ }^{*}\left(\text { DEMPOL }_{\mathrm{i}} \times \mathrm{STEP}_{\mathrm{ij}}\right)+\beta_{15}{ }^{*}\left(\mathrm{DEMPOL}_{\mathrm{i}} \times \mathrm{RAMP}_{\mathrm{ij}}\right) \\
& +\beta_{16}{ }^{*} \text { TRIGGER }_{i}+\beta_{17}{ }^{*} \text { TONE }_{i}+\beta_{18}{ }^{*} \text { ISSUE }_{i}+\beta_{19}{ }^{*} \text { COUNTRY }_{i}+\mu_{\text {it }}
\end{aligned}
$$

Where, in addition to the baseline model introduced earlier, $\mathrm{SIZE}_{\mathrm{i}}$ refers to the estimated size of the demonstration (with our standardized measure calculated from the average of organizer, police and fieldwork researcher estimates, measured in thousands), $\mathrm{DEMPOL}_{\mathrm{i}}$ refers to the aggression of police and demonstrators during the demonstration (initially coded separately as equal to 1 for "not at all", 2 for "not very much", 3 for "somewhat", 4 for "quite" and 5 for "very much", and then added together to create a combined measure which is also standardized), and COUNTER $\mathrm{C}_{\mathrm{i}}$ refers to the presence of a counter-demonstration on the day (coded as equal 


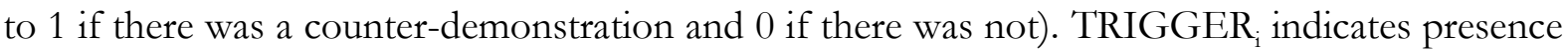
of a trigger event, coded as equal to 1 if there was a direct event causing the demonstration to take place at that specific point in time and 0 if there was not.

Further, the interaction terms in the model enable us to determine whether those contextual factors had a specific effect in the week proximate to the demonstration or in the four weeks following it, serving to either amplify or dampen the level of newspaper coverage. This is important because it allows the dynamic form of the effect to vary, providing further insight into whether contextual effects persist or dissipate after a protest. Specifically, the shape of dynamic response may take the form of a pulse $\left(\mathrm{PULSE}_{\mathrm{ii}}\right)$, step $\left(\mathrm{STEP}_{\mathrm{ii}}\right)$ or ramp $\left(\mathrm{RAMP}_{\mathrm{ii}}\right)$ effect. For example, the $\mathrm{SIZE}_{\mathrm{i}} \times \mathrm{PULSE}_{\mathrm{ij}}$ parameter captures the temporary effect $(t=1)$ of the size of the demonstration, while the $\mathrm{SIZE}_{\mathrm{i}} \times \mathrm{STEP}_{\mathrm{ij}}$ parameter indicates its persisting effect on media coverage $(t>1)$.

The results for the models of dynamic effects of protest context are reported in Table 3. These provide important insights regarding our theory of the dynamics of protest media coverage. Firstly, the interaction of the pulse intervention and the size of the demonstration $\left(\mathrm{SIZE}_{\mathrm{i}} \times\right.$ PULSE $_{\mathrm{ij}}$ ) indicates that larger demonstrations tend to increase the amount of media coverage in the week of the event; the coefficient is equal to $23.74(\mathrm{p}<0.01)$, meaning that a one-unit standard deviation increase in the number of people who attended the demonstration is associated with approximately 24 additional newspaper stories in the week of the protest. In unstandardized terms, around 5,000 additional protestors lead to one extra newspaper story in the week of the protest. Given that the mean size of demonstration for our cases was equal to around 39,000 people, this represents a meaningful effect. The positive and significant interaction of demonstration size with the step intervention $(46.87, \mathrm{p}<0.01)$ further reveals that larger demonstrations tend to have a sustained effect on the level media attention, while the negative and significant effect of the interaction with the ramp intervention $(-15.14, \mathrm{p}<0.01)$ 
indicates that this effect fades over time. Secondly, turning to presence of a counterdemonstration, the negative and significant interaction $(-75.41, \mathrm{p}<0.05)$ with the step intervention $\left(\mathrm{COUNTER}_{\mathrm{i}} \times \mathrm{STEP}_{\mathrm{ij}}\right)$ shows that the level of attention to the protest issues falls in the weeks following the protest. Substantively, this means there are 75.4 fewer mentions of the protest issue in newspaper coverage during weeks after the event. The interaction with the ramp intervention $(26.93, \mathrm{p}<0.05)$ indicates that this attention gradually rebounds, such that the original equilibrium has been restored after a few weeks. Thirdly, the pulse interaction for combined measure of police/protestor aggressiveness (13.67, $\mathrm{p}<0.05)$ shows that demonstrations subject to greater conflict receive more attention in the week of the event, but the step intervention reveals a negative effect $(-23.72, \mathrm{p}<0.05)$, meaning that there is subsequently a fall in the average level of media attention to the issue. The positive and significant ramp intervention $(8.66, \mathrm{p}<0.01)$ indicates that the level of media attention then grows again. Fourthly, and finally, the negative and significant ramp intervention $(-23.49, \mathrm{p}<0.05)$ indicates that media coverage tends to decline more quickly for demonstrations associated with a trigger event. Compared to events where there was not a trigger, there are 23.5 fewer newspaper mentions of the protest issue per week. 
Table 3. Dynamic Model of Contextual Predictors on Media Coverage of Protest Issues

\begin{tabular}{|c|c|c|}
\hline & MEDIA $_{i t}$ & \\
\hline PULSE $_{\mathrm{ij}}$ & $\begin{array}{c}16.73 \\
(13.46)\end{array}$ & $\begin{array}{c}7.25 \\
(7.34)\end{array}$ \\
\hline $\mathrm{STEP}_{\mathrm{ij}}$ & $\begin{array}{l}73.08 \\
(21.74) * *\end{array}$ & $\begin{array}{l}54.74 \\
(11.03) * *\end{array}$ \\
\hline RAMP $_{\mathrm{ij}}$ & $\begin{array}{l}-21.91 \\
(6.82)^{* *}\end{array}$ & $\begin{array}{l}-13.65 \\
(3.68)^{* *}\end{array}$ \\
\hline TONE $_{i}$ & $\begin{array}{c}10.01 \\
(10.77)\end{array}$ & $\begin{array}{c}15.41 \\
(13.94)\end{array}$ \\
\hline $\mathrm{SIZE}_{\mathrm{i}}$ & $\begin{array}{c}2.26 \\
(5.29)\end{array}$ & $\begin{array}{l}-0.18 \\
(4.16)\end{array}$ \\
\hline COUNTER $_{i}$ & $\begin{array}{l}65.55 \\
(10.75)^{* *}\end{array}$ & $\begin{array}{c}72.25 \\
(18.10)^{* *}\end{array}$ \\
\hline DEMPOL $_{i}$ & $\begin{array}{l}27.28 \\
(6.85) * *\end{array}$ & $\begin{array}{l}26.37 \\
(7.81)^{* *}\end{array}$ \\
\hline TRIGGER $_{\mathrm{i}}$ & $\begin{array}{c}-7.00 \\
(20.08)\end{array}$ & $\begin{array}{c}-3.99 \\
(23.29)\end{array}$ \\
\hline $\mathrm{SIZE}_{\mathrm{i}} * \mathrm{PULSE}_{\mathrm{ij}}$ & & $\begin{array}{l}23.74 \\
(7.44) * *\end{array}$ \\
\hline $\mathrm{SIZE}_{\mathrm{i}} * \mathrm{STEP}_{\mathrm{ij}}$ & & $\begin{array}{l}46.87 \\
(11.41) * *\end{array}$ \\
\hline $\mathrm{SIZE}_{\mathrm{i}} * \mathrm{RAMP}_{\mathrm{ij}}$ & & $\begin{array}{l}-15.14 \\
(3.64)^{* *}\end{array}$ \\
\hline COUNTER $_{\mathrm{i}} *$ PULSE $_{\mathrm{ij}}$ & & $\begin{array}{l}-22.00 \\
(21.89)\end{array}$ \\
\hline COUNTER $_{\mathrm{i}} *$ STEP $_{\mathrm{ij}}$ & & $\begin{array}{l}-75.41 \\
(35.55) *\end{array}$ \\
\hline COUNTER $_{\mathrm{i}} * \mathrm{RAMP}_{\mathrm{ij}}$ & & $\begin{array}{c}26.93 \\
(10.54) *\end{array}$ \\
\hline DEMPOL $_{i} *$ PULSE $_{i j}$ & & $\begin{array}{l}13.67 \\
(5.99) *\end{array}$ \\
\hline $\operatorname{DEMPOL}_{\mathrm{i}} * \mathrm{STEP}_{\mathrm{ij}}$ & & $\begin{array}{c}-23.72 \\
(9.25)^{*}\end{array}$ \\
\hline DEMPOL $_{i} *$ RAMP $_{i j}$ & & $\begin{array}{l}8.66 \\
(3.05)^{* *}\end{array}$ \\
\hline TRIGGER $_{\mathrm{i}} *$ PULSE $_{\mathrm{ij}}$ & & $\begin{array}{c}19.75 \\
(23.20)\end{array}$ \\
\hline TRIGGER $_{\mathrm{i}} * \mathrm{STEP}_{\mathrm{ij}}$ & & $\begin{array}{c}55.83 \\
(38.03)\end{array}$ \\
\hline TRIGGER $_{\mathrm{i}} * \mathrm{RAMP}_{\mathrm{ij}}$ & & $\begin{array}{l}-23.49 \\
(11.40)^{*}\end{array}$ \\
\hline ISSUE1: Economic & $\begin{array}{c}4.12 \\
(49.23)\end{array}$ & $\begin{array}{c}-6.71 \\
(45.29)\end{array}$ \\
\hline ISSUE2;: Environment & $\begin{array}{c}24.01 \\
(48.85)\end{array}$ & $\begin{array}{c}14.38 \\
(46.83)\end{array}$ \\
\hline ISSUE3 3 : Rights & $\begin{array}{c}29.36 \\
(49.50)\end{array}$ & $\begin{array}{c}19.60 \\
(46.41)\end{array}$ \\
\hline ISSUE4: Other & $\begin{array}{c}-6.08 \\
(45.74)\end{array}$ & $\begin{array}{l}-21.05 \\
(42.45)\end{array}$ \\
\hline Intercept & $\begin{array}{l}-40.16 \\
(71.53)\end{array}$ & $\begin{array}{l}-40.63 \\
(79.36)\end{array}$ \\
\hline$R^{2}$ & 0.44 & 0.45 \\
\hline Panels & 48 & 48 \\
\hline$N$ & 816 & 816 \\
\hline
\end{tabular}

$* p<0.05 ; * *<<0.01$; Note: the reference category for issue type is those demonstrations that relate to peace. 
We can again plot the marginal effect of each of the contextual predictors (i.e. demonstration size, presence of a counter-demonstration, police/protestor aggressiveness and presence of a trigger event) on the total count of newspaper articles mentioning the protest issue over time. In Figure 4 we present the marginal effects over the six weeks starting from the week before the protest $(\mathrm{t}=-1)$, which indicate the linear combination of the base effect and the pulse, step and ramp interventions. The estimates provide support to the inferences drawn from Table 3. From the upper-left panel, it is evident that the size of demonstration has an immediate impact on level of media attention $(\mathrm{t}=0)$, followed by a further increase in the week after $(\mathrm{t}=1)$ and then a gradual decline in the remaining time period. This is as we hypothesized in $\mathrm{H}_{1}$. The upper-right panel indicates that the short-term effect of presence of a counter-demonstration is, in contrast, to reduce the level of media coverage (at both $\mathrm{t}=0$ and $\mathrm{t}=1$ ), before it slowly rebounds. This does not quite fit the expected pattern for broader social/political conflict, set out in $\mathrm{H}_{2}$, which expected a more immediate increase in media coverage of the protest issue. The pattern for the perceived level of aggressiveness of police and demonstrators, shown in the bottom-left panel is perhaps most interesting. This sees an immediate rise in media coverage during the week of the protest $(t=0)$, followed by a fall in attention the week after $(t=1)$, before media attention increases gradually over subsequent weeks. This is consistent with $\mathrm{H}_{3}$, where the short-term agenda expansion due to violent protest comes at the cost of longer-term dampening of attention, before news coverage of the protest issue is eventually restored to close to its original equilibrium. Finally, the combined marginal effect for presence of a trigger event, shown in the bottom-left panel, reveals this is largely indistinguishable from zero throughout the period, although the effect does decay with time after the protest (from $t=1$ onward). The absence of a temporary increase in media coverage during the week of the demonstration leads to partial rejection of $\mathrm{H}_{4}$, but importantly the effect decays as predicted. 
Figure 4. Marginal Effect of Predictors on Media Coverage of Protest Issues
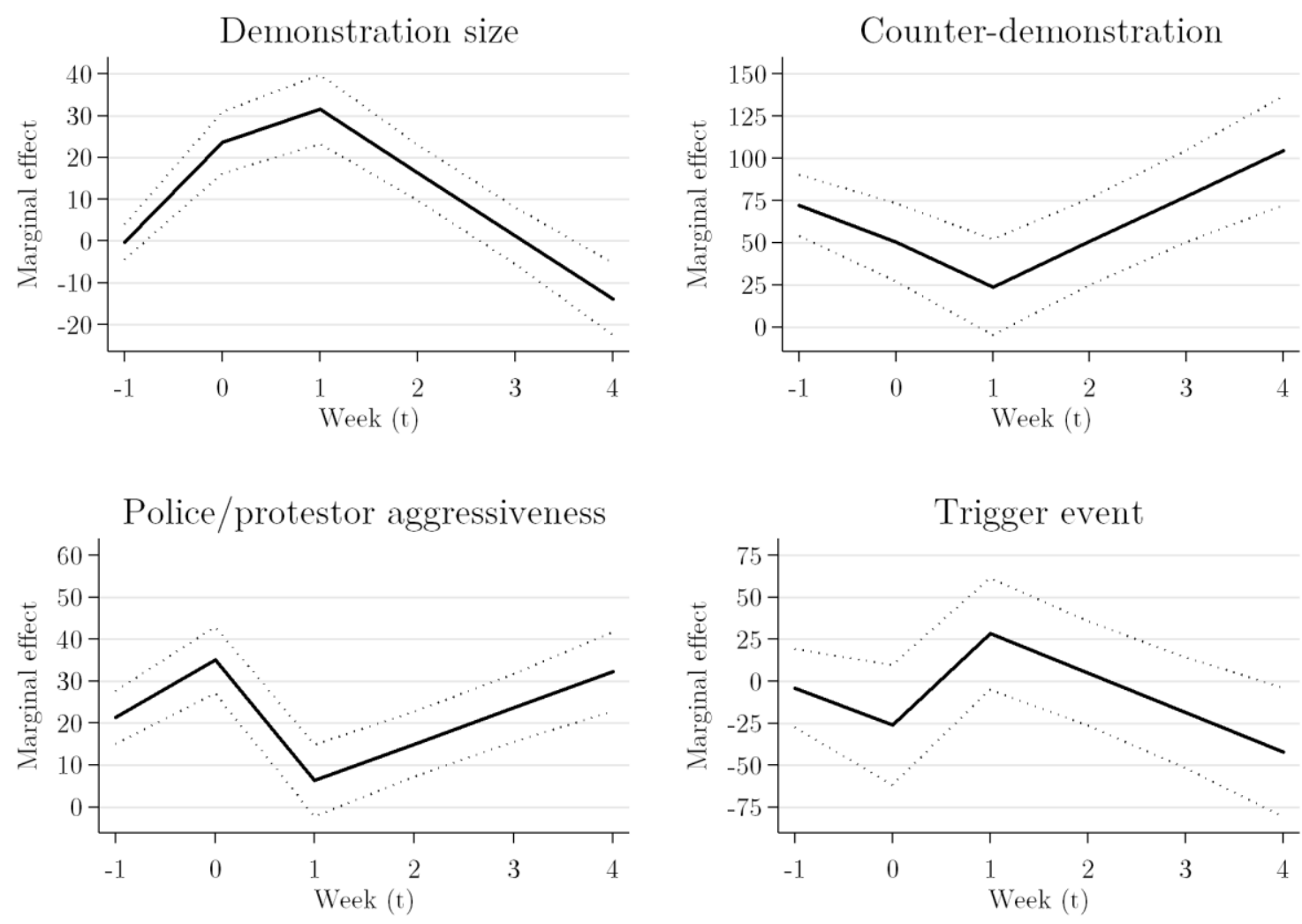

A comparison of the media effects of two demonstrations

We further illustrate our findings with reference to two demonstrations with significantly different types of media effect from the Climate Change Demonstration in Utrecht (2010, protest 15) and the $1^{\text {st }}$ May Demonstration in Barcelona (2010, protest 28) (see panels in Figure 2). Both have a hybrid effect, but this manifests in different ways for the two issues. In relation to the climate change demonstration, attention to climate change tails off after a small peak, going from 20 newspaper articles at 10-weeks before the demonstration to 34 articles during the week of the demonstration and down to only 14 articles four-weeks after. In contrast, attention to social justice issues is higher in the aftermath of the $1^{\text {st }}$ May demonstration (178 newspaper articles four-weeks after) compared to the week of the demonstration (99 articles).

We selected these two demonstrations for comparison because, in addition to having different media trajectories, they are similar in many other respects: both were supported by a significant 
and well-established social movement sector active in protest and both were part of a broader cycle of action (but with no other significant mobilisations in the 4-weeks after each protest). There have been fairly regular protests on these two issues over the past 10 years in the respective countries. In this way, we have a measure of control over 'media cascades' (Seguin 2016). The two demonstrations are also similar in terms of the behaviour of police and demonstrators. For both demonstrations, the police were somewhat cheerful and not at all aggressive, whereas the demonstrators were not very cheerful and fairly disorderly.

Yet there are also some important differences. The $1^{\text {st }}$ May event was a march through the centre of Barcelona, attracting approximately 8,300 protesters. Although it was a fairly large demonstration, it was smaller than expected because of poor weather. The climate demonstration in Rotterdam was a combination of a demonstration and festival - there were film screenings, presentations and stalls. It attracted approximately 4,200 protesters. It was timed to coincide with the United Nations Climate Change Conference (COP16), which we would classify as a trigger event. The $1^{\text {st }}$ May demonstration did not have a similar coincidental trigger event. The protests also differed in terms of anticipated violence. In Spain, demonstrations for social justice frequently turn violent, whereas climate change demonstrations in The Netherlands are mostly peaceful.

We hypothesized that protests focused on socially and politically contentious issues and those with a trigger event might increase attention to protest issues, but our case studies corroborate the rejection of these hypotheses. Climate change is highly contested and the demonstration was organised specifically to coincide with a trigger event (COP15), and yet attention to climate change tails off in the aftermath of the protest. The $1^{\text {st }}$ May demonstration did not have a trigger event and yet managed to sustain media attention in the longer term.

Our hypotheses on violence and demonstration size are supported, however. The threat of violence at the $1^{\text {st }}$ May demonstration might have led to the small increase in coverage of social 
justice in week 0 , but the absence of violence itself perhaps allowed coverage of social justice to be sustained over time. Moreover, the Barcelona demonstration was almost twice as large as the Utrecht one. Our quantitative findings and qualitative comparison both illustrate the importance of protest size in sustaining attention to protest issues in the longer-term.

\section{Conclusions}

Media coverage is highly important for raising awareness of the political issues promoted by protest movements. Indeed, as Lipsky (1968, p. 1151) points out "the communications media set the limits of protest action." The effectiveness of protest directed at raising public awareness, changing attitudes or influencing policy therefore relies upon the extent to which it is able to draw attention to the public spectacle of rallies, marches, sit-ins, meetings and riots - and sustain that attention in future time periods. Such protest events underpin the captivating and contagious power of political conflict, famously observed by Schattschneider (1960). The question of why some protests are able to secure and sustain coverage on the agenda is crucial for understanding the opportunities open to social movements and interest groups who wish to influence the decision-making agenda.

In this paper we have argued that the agenda-setting power of street demonstrations must be understood with reference to their context, and that this influence on the societal agenda is structured in time. Departing from protest event studies, which use protest as a unit of analysis (often as a dependent variable), we have compared and contrasted newspaper coverage associated with nearly fifty large street demonstrations in nine countries. We find that coverage of protest issues is sustained over time. It might be expected that it is hard for a demonstration to impact issue coverage beyond the immediate episodic timeframe, as the protest signal is lost amidst the multitude of other, new information signals. Our novel approach to modelling the dynamic effects of protest on media agendas uses protest issues as the dependent variable. This enables us to develop and find support for our theory of the dynamic relationship between 
demonstrations and coverage of protest issues. Differing from existing studies, our use of news coverage as a dependent variable and time series modelling allows us to show that demonstrations can have an enduring impact on media agendas, lasting several weeks beyond the protest event.

Using time series cross-sectional analyses we find that demonstrations increase media coverage of protest issues but also that this effect decays quickly over time, so the time window for exerting pressure on the media agenda is short. In terms of the demonstration context, we find that demonstration size and the aggressiveness of police and demonstrators lead to increased media coverage. This is consistent with Schattschneider's (1960) argument regarding the contagion of conflict and its agenda-setting power in widening the scope of (issue) conflict. In line with Schattschneider, we also anticipated that demonstrations would have a larger impact in mobilizing the media agenda on issues that are more heavily contested. It is therefore surprising that the presence of a counter-demonstration significantly reduced media coverage of protest issues in the longer-term. One possible explanation may be that social conflict is not fully captured by the staging of a counter demonstration. A counter-demonstration might not be observed on the day of a demonstration even when a counter movement is active. To address this limitation, future research might combine our approach with measurement of contextual information about inter-group conflict and sectional interests. Nonetheless, we have marked a new direction in this field by theorising and illustrating that the effects of contextual variables on the agenda-setting power of protest are structured in time. The effect of demonstration size and aggressiveness is greatest on the media agenda during the week during or following the protest itself, suggesting a short-lived spike in media attention. In the weeks following the protest, however, more aggressive behavior by police and protestors depresses the level of media coverage of the protest issue, though this effect dissipates over time. 
Our work makes a contribution to the social movements and protest literature because it allows for a more nuanced understanding of the notion of "discursive eruption" (Gaby and Caren, 2016). Gaby and Caren (2016) suggested that the protest events of radical organisations have an indirectly positive effect on sustained newspaper coverage. Our findings offer modest support for this, but with the nuance that violence and/or aggression can lessen the potential for "discursive eruption", even if violence and aggression lead to a media attention spike in the short-term. There is potential to build yet further on our work by comparing the media agendas of different types of protest. We focused on large-scale protests and we expect that strikes, boycotts, riots and other forms of offline and online protest will generate and sustain coverage differentially. Nonetheless, violence, aggression, size and social contestation can be expected to affect coverage of different forms of protest in similar dynamic ways. A violent strike, for example, might generate media attention in the short-term, though will likely be followed by a rapid decline. Moreover, our findings suggest the potential for further work that takes a dynamic approach to the relationship to the interplay between protest and media agendas. Just as protest influences the media agenda, it is altogether feasible that the media agenda also influences the degree and type of protest (giving rise to positive feedback processes whereby media coverage leads to further protest on an issue). Overall, our findings demonstrate both that context matters for the influence of protest over the media agenda, but also that this influence is dynamic, not static. 


\section{References}

Andrews, K.T., \& Biggs, M. (2006). The dynamics of protest diffusion: Movement organizations, social networks, and news media in the 1960s sit-ins. American Sociological Review, 71(5), 752777.

Andrews, K.T., \& Caren, N. (2010). Making the news: Movement organizations, media attention, and the public agenda. American Sociological Review, 75(6), 841-866.

Anduiza, E., \& Cristancho, C. (2011). Our sample of demonstrations. Presentation to Caught in the Act of Protest: Contextualizing Contestation project meeting, April 2011.

Baumgartner, F.R., \& Jones, B.D. (1993). Agendas and Instability in American Politics. Chicago: University of Chicago Press.

Barranco, J., \& Wisler, D. (1999). Validity and systematicity of newspaper data in event analysis. European Sociological Review, 15(3), 301-322.

Biggs, M. (2018). Size matters: Quantifying protest by counting participants. Sociological Methods and Research, 47(3), 351-383.

Beck, N., \& Katz, J.N. (1995). What To Do (and Not To Do) with Time-Series Cross-Section Data. American Political Science Review, 89(3), 634-647.

Bennett, L. (1996). An introduction to journalism norms and representations of politics. Political Communication, 13(4), 373-384.

Bennett, L. (2003). New media power: The Internet and global activism. In N. Couldry \& .J. Curran (Eds.) Contesting Media Power (pp. 17-37). Lanham: Rowman \& Littlefield.

Bennett, L. (2016). News: The Politics of Illusion. Tenth Edition. Chicago: University of Chicago Press.

Box, G.E.P., \& Tiao, G.C. (1975). Intervention Analysis with Applications to Economic and Environmental Problems. Journal of the American Statistical Association, 70(349), 70-79.

Boydstun, A. (2013). Making the News: Politics, the Media and Agenda-Setting. Chicago: University of Chicago Press. 
Boykoff, M.T. (2007). Flogging a Dead Norm? Media Coverage of Anthropogenic Climate Change in United States and United Kingdom, 2003-2006. Area, 39(4), 470-481.

Choi, I. (2001). Unit Root Tests for Panel Data. Journal of International Money and Finance 20, 249272.

Donson, F., Chesters, G., Welsh, I. \& Tickle, A. (2004). Rebels with a cause, folk devils without a panic: Press jingoism, policing tactics and anti-capitalist protest in London and Prague. Internet Journal of Criminology. http://www.internetjournalofcriminology.com/donson $\% 20$ et $\% 20$ al $\% 20-\% 20$ folkdevils.pdf

Downs, A. (1972). Up and Down with Ecology: The Issue-Attention Cycle. The Public Interest, 28(Summer), 38-50.

Earl, J., Martin, A., McCarthy, J.D. \& Soule. S.A. (2004). The use of newspaper data in the study of collective action. Annual Review of Sociology, 30, 65-80.

Gaby, S., \& Caron, N. (2016). The Rise of Inequality: How Social Movements Share Discursive Fields. Mobilization: An International Quarterly, 21(4), 413-429.

Galtung, J. \& Ruge, M. (1973). Structuring and Selecting News. In Stanley Cohen and Jock Young (Eds.) The Manufacture of News (pp. 459-476). London: Constable.

Gandy, O.H., Jr. (1982). Beyond Agenda Setting: Information subsidies and public policies. Norwood, NJ: Ablex Publishing.

Gamson, W. (1975). The Strategy of Social Protest. Homewood, Illinois: Dorsey Press.

Iyengar, S., \& Kinder, D.R. (1987). News That Matters: Television and American Opinion. Chicago: University of Chicago Press.

Iyengar, S., (1991). Is Anyone Responsible? How Television Frames Political Issues. Chicago: University of Chicago Press.

Jones, B.D., \& Baumgartner, F.R. (2005). The Politics of Attention: How Government Prioritizes Problems. Chicago: University of Chicago Press.

Kingdon, J. (1984). Agendas, Alternatives and Public Policies. New York: HarperCollins. 
Klandermans, B., Van Stekelenburg, J., Van Troost, D., Van Leeuwen, A., Walgrave, S., Verhulst, J., Van Laer, J. \& Wouters, R. (2010). Manual for Data Collection on Protest Demonstrations, Brussels/Antwerp: Caught in the Act of Protest, Contextualising Contestation.

Koopmans, R. (2004). Movements and media: Selection processes and evolutionary dynamics in the public sphere. Theory and Society, 33(3/4), 367-391.

Koopmans, R., \& Olzak, S. (2004). Discursive opportunities and the evolution of right-wing violence in Germany. American Sociological Review, 110(1), 198-230.

Kreisi, H., Koopmans, R., Duyvendak, J.W. \& Giugni, M.G. (1995). New Social Movements in Western Europe: A Comparative Analysis. Minneapolis: University of Minnesota Press.

Lipsky, M. (1968). Protest as a political resource. American Political Science Review, 62(4), 1144-1158. Matusitz, J., \& Breen, G-M. (2012). An examination of pack journalism as a form of groupthink. Journal of Human Behaviour in the Social Environment, 2(7), 896-915.

Maney, G., \& Oliver, P.E. (2001). Finding collective events: Sources, searching, timing. Sociological Methods and Research, 30(2), 131-169.

McCarthy, J.D., McPhail, C. \& Smith, J. (1996). Images of protest: Dimensions of selection bias in media coverage of Washington demonstrations, 1982 and 1991. American Sociological Review, 61(3), 478-499.

Olzak, S. (1989). Analysis of Events in the Study of Collective Action. Annual Review of Sociology 15, 119-141.

Schattschneider, E.E. (1960). The Semi-Sovereign People: A Realist's View of Democracy in America. New York: Holt, Rinehart \& Winston.

Seguin, C. (2016). Cascades of Coverage: Dynamics of Media Attention to Social Movement Organizations. Social Forces, 94(3), 997-1020.

Shoemaker, P.J., \& Reese, S.D. (1996). Mediating the Message: Theories of Influences on Mass Media Content [2nd Edition]. New York: Longman. 
Smith, J., McCarthy, J.D., McPhail, C. \& Augustyn, B. (2001). From protest to agenda building: description bias in media coverage of protest events in Washington D.C. Social Forces, 79(4), 1397-1423.

Snyder, D., \& Kelly, W.R. (1977). Conflict intensity, media sensitivity and the validity of newspaper data. American Sociological Review, 42(1), 105-123.

Soroka, S. (2012). The Gatekeeping Function: Distributions of Information in Media and the Real World. Journal of Politics, 74(2), 514-528.

Soroka, S. (2014). Negativity in Democratic Politics: Causes and Consequences. Cambridge: Cambridge University Press.

Tarrow, S. (1994). Power in Movement: Social Movements, Collective Action and Politics. Cambridge: Cambridge University Press.

van Zoonen, E.A. (1992). The women's movement and the media: Constructing a public identity. European Journal of Communication, 7(4), 453-477.

Vliegenthart, R., \& Walgrave, S. (2011). When the media matter for politics. Partisan moderators of mass media's agenda-setting influence on Parliament in Belgium. Party Politics, 17(3), 321 342.

Vliegenthart, R., Walgrave, S., Hutter, S., Jennings, W., Grossman, E., Giugni, M., Wouters, R., Varone, F., Tresch, A., Gava, R., Brouard, S., Chaques, L. \& Breunig, C. (2016). The Media as a Dual Mediator of the Political Agenda Setting Effect of Protest. A Longitudinal Study in Six West-European Countries. Social Forces, 95(2), 837-859.

Walgrave, S., \& Vliegenthart, R. (2012). The Complex Agenda-Setting Power of Protest: Demonstrations, Media, Parliament, Government and Legislation in Belgium, 1993-2000. Mobilization, 17(2), 129-156. 
Appendix 1. Description of Variables

\section{Dependent variables}

Media coverage to general protest issue: the number of newspaper articles identified during a given week based on a search of terms related to the general theme of the demonstration. Where a protest addresses multiple issues, we use the total number of articles to capture the overall size of the media agenda.

\section{Independent variables}

Media tone: coders assigned a score for the overall negativity of newspaper coverage of the demonstration in the sampled articles. Specifically, the coders were asked “... how would you describe the coverage of the demonstration in general?" where the possible responses were "Largely positive/sympathetic" (1), "Largely neutral and descriptive" (2), "Largely negative/unsympathetic" (3), "Largely a mixture of negative, positive and neutral" (4), "Largely a mixture of negative and positive" (5), "Largely a mixture of negative and neutral" (6) and "Largely a mixture of positive and neutral" (7). We recoded this variable on a scale from 1 to 5 , such that positive coverage [1] was equal to 1 , positive-neutral coverage [7] was equal to 2 , mixed or neutral coverage $[2,4,5]$ was equal to 3 , negative-neutral coverage [6] was equal to 4 , and negative coverage [3] was equal to 5 .

Demonstration size: the size of demonstration was calculated as the average of the police, media and researchers' estimates of the number of participants.

Counter-demonstration: this was coded as equal to 1 if there was a counter-demonstration and 0 if there was not. 
Appendix 2. List of demonstrations

\begin{tabular}{|c|c|}
\hline 1 & Climate Change (Brussels) \\
\hline 2 & March for Work (Brussels) \\
\hline 3 & No to Austerity (Brussels) \\
\hline 4 & No Government, Great Country (Brussels) \\
\hline 5 & Non-Profit Demonstration (Brussels) \\
\hline 6 & Not in Our Name (Brussels) \\
\hline 7 & We have alternatives (Brussels) \\
\hline 8 & Prague Pride (Prague) \\
\hline 9 & Stop the Government (Prague) \\
\hline 10 & The End of Godfathers (Prague) \\
\hline 11 & Climate March (Copenhagen) \\
\hline 12 & Anti Nuclear Manifestation (Beznau) \\
\hline 13 & Anti-nuclear (Mühleberg) \\
\hline 14 & Retirement demonstration (Rotterdam) \\
\hline 15 & Climate demo (Utrecht) \\
\hline 16 & Student demo 1 (Amsterdam) \\
\hline 17 & Culture demo Amsterdam (Amsterdam) \\
\hline 18 & Culture demo Utrecht (Utrecht) \\
\hline 19 & Student demo 2 (The Hague) \\
\hline 20 & Together strong for public work (The Hague) \\
\hline 21 & Anti Nuclear demo (Amsterdam) \\
\hline 22 & Military demo (The Hague) \\
\hline 23 & Stop budget cuts (care \& welfare) (The Hague) \\
\hline 24 & Occupy Netherlands (Amsterdam, Utrecht, Rotterdam) \\
\hline 25 & Demonstration against language decree (Santiago de Compostela) \\
\hline 26 & Against the Europe of Capital, Crisis and War (Barcelona) \\
\hline 27 & Demonstration Against Abortion (Madrid) \\
\hline 28 & 1st May, Labour Day (Barcelona) \\
\hline 29 & Demonstration against the new labour law (Santiago de Compostela) \\
\hline 30 & We are a nation, we decide (Barcelona) \\
\hline 31 & Against Labor Law (Madrid) \\
\hline 32 & Celebration May Day (Vigo) \\
\hline 33 & Real Democracy Now! We are not good in the hands of politicians and bankers! (Madrid) \\
\hline 34 & May 1 March, Left Party (Stockholm) \\
\hline 35 & May 1 March, Social Democratic Party (Stockholm) \\
\hline 36 & Against racist politics (Stockholm) \\
\hline 37 & Anti-nuclear demonstration (Stockholm) \\
\hline 38 & May Day (Left Party) (Malmö) \\
\hline 39 & May Day (SAP/LO) (Malmö) \\
\hline 40 & May Day (Left Party) (Gothenburg) \\
\hline 41 & May Day (Social Democratic Party/LO) (Gothenburg) \\
\hline
\end{tabular}




\begin{tabular}{|l|l|}
\hline 42 & Rainbow Parade (LGBTQ festival) (Gothenburg) \\
\hline 43 & Women demonstration Geneva (Geneva) \\
\hline 44 & National Climate March (London) \\
\hline 45 & May Day Labour March (London) \\
\hline 46 & Take Back Parliament (London) \\
\hline 47 & Million Women Rise (London) \\
\hline 48 & 'TUC's March for the Alternative: Jobs, Growth, Justice (London) \\
\hline
\end{tabular}

